\title{
Old habits die hard; does early urinary catheter removal affect kidney size, bacteriuria and UTI after renal transplantation?
}

\author{
Roghayeh Akbari ${ }^{1}$, Sedigheh Rahmani Firouzi ${ }^{2}$, Abazar Akbarzadeh-Pasha ${ }^{1^{*}}$ \\ ${ }^{1}$ Clinical Research Development Unit, Ayatollah Rohani Hospital, Babol University of Medical Sciences, Babol, Iran \\ ${ }^{2}$ Babol University of Medical Sciences, Babol, Iran
}

\section{A R T I C L E I N F O}

Article Type:

Original

\section{Article History:}

Received: 5 September 2016

Accepted: 4 November 2016

Published online: 20 November 2016

Keywords:

Kidney transplantation

Bacteriuria

Urinary tract infection

\begin{abstract}
A B S T R A C T
Introduction: Renal transplantation is the treatment of choice in chronic renal failure patients.

Objectives: The purpose of this study was to evaluate the impact of urinary catheter removal time on transplanted kidney size and incidence of asymptomatic bacteriuria and urinary tract infections (UTIs).

Patients and Methods: This retrospective cohort study evaluated the clinical outcomes of 109 consecutive live donor renal transplant recipients from December 2011 to July 2014. Routine ultrasound examinations were performed on donor's kidney prior to operation and one month later. Kidney volume was calculated. UTI and bacteriuria were evaluated one month later. Patients were divided into two groups based on time of Foley catheter removal (before and after fifth day posttransplantation).

Results: In this study 74 males (67.9\%) and 35 females (32.1\%) were evaluated. Sixty-six patients $(57.92 \%)$ were in group 1 . None of the patients with positive urine culture had UTI but bacteriuria occurred in all of them (21.1\%). Bacteriuria time after transplantation and catheter removal was significantly later in group 1 and it was not different in female group but they were later in male group. The mean renal volume increase was positively correlated to renal transplant recipient and donor's age and donor's body mass index $(\mathrm{BMI})(P<0.05)$. Conclusion: This study showed that the time of catheter removal after kidney transplantation does not affect incidence of UTI but increases the probability of bacteria in men whose catheter was removed within 5 days after transplantation. We also found that the renal volume change is not associated with catheter removal time and bacteriuria.
\end{abstract}

\section{Implication for health policy/practice/research/medical education:}

In a study on 109 patients, we found the time of catheter removal after kidney transplantation does not affect incidence of UTI but increases the probability of bacteria in men whose catheter was removed within 5 days after transplantation. We also found that the renal volume change is not associated with catheter removal time and bacteriuria.

Please cite this paper as: Akbari R, Rahmani Firouzi S, Akbarzadeh-Pasha A. Old habits die hard; does early urinary catheter removal affect kidney size, bacteriuria and UTI after renal transplantation? J Renal Inj Prev. 2017;6(1):43-48. DOI: $10.15171 /$ jrip.2017.08.

\section{Introduction}

Renal transplantation is the treatment of choice in chronic renal failure patients and treatment outcomes varies in different centers (1). Urinary tract infection (UTI) is the most common infection following renal transplantation with a prevalence of $35 \%$ to $79 \%$ and accounts for about $40 \%-50 \%$ of all infectious complications $(2,3)$. It is associated with the development of acute cellular rejection, impaired allograft function, allograft loss, and death. Morbidity and mortality from UTI can be caused by recurrent and/or severe sepsis (4). The importance of this concern is further underscored by the fact that about $60 \%$ of bacteremia among renal transplant recipients originates from urinary tract, so its prevention is important (5). Risk factors for UTI include old age, female gender, cadaveric donor, UTI before transplantation, prolonged hemodialysis period, polycystic renal disease, diabetes mellitus, prolonged postoperative bladder catheterization, 
reflux kidney disease immunosuppression, allograft trauma, and technical complications associated with urethral anastomosis (6).

All aspects of pre- and postoperative care of renal transplant recipients need to be evaluated to ensure optimal patient safety and clinical outcomes. Catheterization of the urinary bladder during renal transplantation is essential because postoperative urine output measurement with Foley catheterization is essential (7). Its benefits include preparation of the bladder for anastomosis and monitoring subsequent urinary output (8). The optimal time to remove the catheter postoperatively is controversial. The trend in most institutions is to err on the side of leaving the catheter in for a longer period of time, to ensure consistent urine output (7). Some recommend catheter removal on postoperative day 5 (9). The risks of prolonged Foley catheterization are manifold. It increases the risk of catheter-associated UTI especially in newly transplanted patients receiving immunosuppression. It also decreases patient mobility which increases the risk of venous thromboembolism, pneumonia, and hospital length of stay. It is suggested to remove the catheter on postoperative day 1 in live donor renal transplant recipients to prevent its complications (7).

Bladder drainage with Foley catheterization may allow the probable leak to heal before becoming clinically manifest. Abnormalities of kidney size occur in many renal diseases. The determination of normal renal size in any population is important in the diagnosis, treatment and prognosis of renal disease (10). Also, kidney size using either renal length, volume, and cortical thickness as a unit of measurement represent renal function and are used frequently as the basis for making clinical decisions in the evaluation and follow up of kidney transplant patients (11). The most accurate of these parameters is renal volume, as the shape of kidney varies considerably. Serial measurements also can provide information regarding disease progression or stability (12).

Because therapeutic decisions frequently are based on the results of these measurements, accurate measurement of renal length and volume are of increasing importance (12).

\section{Objectives}

The purpose of this study was to evaluate the impact of urinary catheter removal time on transplanted kidney size changes and incidence of asymptomatic bacteriuria and UTIs one month following the operation.

\section{Patients and Methods}

In this retrospective cohort study we reviewed the clinical outcomes of 127 consecutive live donor renal transplant recipients from December 2011 until July 2014. In case of neurogenic bladder, history of recurrent UTI, history of UTI one month prior to renal transplantation, history of frequent catheterizations, abnormal urogenital system, history of vesicoureteral reflux, loss of kidney transplant due to antibody mediated rejection and frequent catheter manipulation after transplantation, patients were excluded from the study. Finally, 109 patients remained.

\section{Kidney transplantation}

All the surgical procedures were performed by the same surgeon and surgery team in the same center from live donors. The kidney graft was placed in iliac cavity close to the previously dissected external iliac vessels. Anastomosis of renal vein to the common or external iliac vein and renal artery to internal or external iliac artery were performed. In all patients a silicon double J stent or Nelaton catheter $(\mathrm{Ch} / \mathrm{Fr} 8)$ was inserted at operation room as urethral stent. The time of urethral stent removal was similar in all patients. The initial dose of immunosuppressant was given immediately after the transplantation. Subsequently, the patients were kept on maintenance dose and the immunosuppressant protocol were the same in all patients.

\section{Transplanted kidney size}

Routine ultrasound examinations were performed on donor's kidney prior to operation and by one radiologist. Upper and lower poles of kidney were identified and their distance was used as renal length (the distance between the highest and lowest levels of kidney). The anteroposterior (AP) diameter of the kidney in the middle one third was considered as renal cortical thickness.

The renal width represented the average measurement from the widths at the hilum and $1 \mathrm{~cm}$ above and $1 \mathrm{~cm}$ below the hilum. These widths were perpendicular to the AP diameter. Thus, the volume was calculated according to the equation for an ellipsoid (13): $0.523 \times L \times W \times A P$. Here, $L$ is the maximum bipolar diameter (BPD); $W$ is the renal width and $A P$ is the anteroposterior diameter.

Ultrasound examination was performed one month after the operation on transplanted kidney and all diameters were remeasured and the volume was recalculated.

\section{Bacterial identification}

UTI and bacteriuria were evaluated one month after the transplantation. Qualitative urine cultures were performed on blood agar and McConkey agar (Himedia, India) and for grown bacteria, biochemical identification tests and colony count were done as per standard protocol. The first urine sample for urine analysis and culture was obtained within 12 hours following catheter removal and then, routine urine cultures were performed on Saturdays and Tuesdays by the patients from midstream urine. During the catheterization, in case of urinary signs, a sample for urine analysis and culture was obtained. A positive result for UTI was considered when the bacterial counts were recorded more than $10^{5}$ bacterial colony-forming unit per milliliter $(\mathrm{CFU} / \mathrm{mL})$ on urine culture with local urinary symptoms. Local urinary symptoms included dysuria, frequency, or urgency, suprapubic tenderness and fever (2).

Asymptomatic bacteriuria was defined by the presence of more than $10^{5} \mathrm{CFU} / \mathrm{mL}$ of urine on urine culture with no 
local or systemic symptoms of UTI (4).

Antibiogram was performed for all urine cultures and the pathogen susceptibility was obtained. All urine cultures were performed in one laboratory. Antibiotic prophylaxis with cefazolin was done and after the catheter removal, amikacin was prescribed and cotrimoxazol was continued. Patients with UTI were treated with meropenem.

\section{Catheterization}

For all kidney graft recipients, a Foley catheter was inserted in the operation room prior to renal transplantation which was removed within 5 days of transplantation. Prolonged use of Foley catheter was defined as the use of a Foley catheter beyond day 5 after transplantation. The physician removed the catheter randomly whenever decided and without being informed of the study protocol. Then, the patients were divided into two groups. For the first group, the catheter was removed before 5 days postoperation and for the second group this time was after the fifth day.

Finally, data including age, gender, height, weight, history of diabetes mellitus and thymoglobulin prescription for the renal transplant recipient were recorded. BMI was calculated using weight divided by the square of the body height $\left(\mathrm{kg} / \mathrm{m}^{2}\right)$. Body surface area was calculated using the formula (14): $71.84 \times$ height $(\mathrm{m})^{0.725} \times$ weight $(\mathrm{kg})^{0.425}$.

\section{Ethical issues}

The research followed the tenets of the Declaration of Helsinki and informed consent was obtained. The research was approved by the ethical committee of Babol University of Medical Sciences (\#923649, 2013).

\section{Statistical analysis}

Data was analyzed by SPSS version 17.0. A descriptive analysis was performed, defining the baseline population characteristics and exploring the main results in the cohort. Chi-square, $t$ test and logistic regression tests were used to analyze different factors in both groups. A $P$ value less than 0.05 was considered being statistically significant.

\section{Results}

This study consisted of 109 patients, 74 males $(67.9 \%)$ and 35 females (32.1\%) with the mean age of $42.0 \pm 13.05$ years for donors and $28.17 \pm 4.20$ years for renal transplant recipients. The most common reasons for end-stage renal disease were unknown (33\%) and hypertension (30.3\%). Sixty-six patients (57.92\%) were in group 1 and 46 patients (41.07\%) were in group 2.

Donor and recipient gender, thymoglobulin prescription, recipient diabetes and right and left transplanted kidney sizes were not in both groups (Table 1). Also, the mean age, BMI and body surface area (BSA) were not statistically different between two groups (Table 2).

None of the patients with positive urine culture had UTI symptoms but bacteriuria occurred in all of them (21.1\%). The mean catheter removal time in group 1 was $4.59 \pm 0.687$ days and $7.67 \pm 2.522$ days in group 2. As
Table 1. Qualitative variables in both groups

\begin{tabular}{|c|c|c|c|}
\hline & $\begin{array}{c}\text { Group } 1 \\
(n=63)\end{array}$ & $\begin{array}{c}\text { Group } 2 \\
(n=46)\end{array}$ & $P$ value \\
\hline Donor gender & & & 0.610 \\
\hline Male & $47(74.6 \%)$ & $37(80.4 \%)$ & \\
\hline Female & $16(25.4 \%)$ & $9(19.6 \%)$ & \\
\hline Recipient gender & & & 0.474 \\
\hline Male & $44(69.8 \%)$ & $30(65.2 \%)$ & \\
\hline Female & $19(30.2 \%)$ & $16(34.8 \%)$ & \\
\hline Thymoglobulin prescription & $6(9.5 \%)$ & $9(20.0 \%)$ & 0.121 \\
\hline Recipient diabetes & 9 (14.3\%) & $8(17.4 \%)$ & 0.659 \\
\hline Transplanted kidney & & & 0.680 \\
\hline Right & $10(15.9 \%)$ & $6(12.0 \%)$ & \\
\hline Left & $53(84.1 \%)$ & $40(87.0 \%)$ & \\
\hline
\end{tabular}

Table 2. Quantitative variables and the mean time to bacteriuria in both groups

\begin{tabular}{|c|c|c|c|}
\hline & $\begin{array}{l}\text { Group } 1 \\
(n=63)\end{array}$ & $\begin{array}{c}\text { Group } 2 \\
(n=46)\end{array}$ & $P$ value \\
\hline \multicolumn{4}{|l|}{ Age (year) } \\
\hline Donor & $27.92 \pm 4.16$ & $28.50 \pm 4.32$ & 0.480 \\
\hline Recipient & $42.52 \pm 12.7$ & $41.28 \pm 13.62$ & 0.620 \\
\hline \multicolumn{4}{|l|}{ BMI (kg/m²) } \\
\hline Donor & $24.91 \pm 3.51$ & $24.64 \pm 3.73$ & 0.703 \\
\hline Recipient & $24.04 \pm 3.78$ & $24.93 \pm 4.76$ & 0.280 \\
\hline \multicolumn{4}{|l|}{$\operatorname{BSA}\left(m^{2}\right)$} \\
\hline Donor & $650.54 \pm 59.76$ & $652.82 \pm 68.87$ & 0.854 \\
\hline Recipient & $608.86 \pm 75.28$ & $618.11 \pm 81.58$ & 0.542 \\
\hline $\begin{array}{l}\text { Bacteriuria time post- } \\
\text { donation (day) }\end{array}$ & $2.37 \pm 5.21$ & $0.65 \pm 2.00$ & 0.020 \\
\hline $\begin{array}{l}\text { Bacteriuria time after } \\
\text { catheter removal (day) }\end{array}$ & $1.33 \pm 3.95$ & $0.09 \pm 0.354$ & 0.016 \\
\hline \multicolumn{4}{|l|}{ Renal length (cm) } \\
\hline Donor & $11.81 \pm 0.76$ & $11.86 \pm 0.78$ & 0.760 \\
\hline Recipient & $115.76 \pm 13.61$ & $114.52 \pm 10.58$ & 0.608 \\
\hline \multicolumn{4}{|l|}{ Renal width $(\mathrm{cm})$} \\
\hline Donor & $4.75 \pm 0.66$ & $4.84 \pm 0.70$ & 0.481 \\
\hline Recipient & $5.05 \pm 0.99$ & $5.08 \pm 0.88$ & 0.862 \\
\hline \multicolumn{4}{|l|}{ AP diameter } \\
\hline Donor & $5.80 \pm 0.92$ & $5.90 \pm 1.26$ & 0.672 \\
\hline Recipient & $6.21 \pm 1.10$ & $6.00 \pm 0.79$ & 0.280 \\
\hline \multicolumn{4}{|l|}{ Renal volume $\left(\mathrm{cm}^{3}\right)$} \\
\hline Donor & $173.32 \pm 49.94$ & $181.21 \pm 64.08$ & 0.470 \\
\hline Recipient & $168.20 \pm 79.95$ & $188.87 \pm 66.43$ & 0.520 \\
\hline
\end{tabular}

Abbreviations: BMI, body mass index; AP, anteroposterior; BSA, body surface area.

shown in Table 2, kidney size of donor and recipients were not different. Also, the kidney sizes were not statistically different based on gender $(P>0.05)$.

Bacteriuria time after transplantation and catheter removal was statistically different in both groups and was later in group one which removed the catheter sooner. After considering gender, bacteriuria time after transplantation and catheter removal were not different in female group ( $P=0.462$ and $P=0.098$, respectively) but they were later in male group $(P=0.014$ and $P=0.049$, respectively). Of 
23 cases $(21.1 \%)$ with bacteriuria, $17(73.9 \%)$ were in group 1 and 6 ones $(26.1 \%)$ were in group $2(P=0.078)$. Five $(21.74 \%)$ of them occurred during catheterization and 18 (78.26\%) occurred after catheter removal. Of these, the mean renal volume increased $16.27 \mathrm{~cm}^{3}$ which was not different from patients without bacteriuria $\left(17.96 \mathrm{~cm}^{3}\right.$ increase, $P=0.922$ ).

Logistic regression for the association between bacteriuria and age, gender, thymoglobulin prescription, diabetes mellitus and catheter removal time showed that only gender (odds ratio $[\mathrm{OR}]=2.99,95 \% \mathrm{CI}=1.13-8.91, P=0.031$ ) and catheter removal time $(\mathrm{OR}=0.30,95 \% \mathrm{CI}=0.09-0.92$, $P=0.039$ ) were significantly associated with bacteriuria so that in women, it was three times higher than men. The most common isolated bacteria were gram negative bacilli as follows: Escherichia coli (15.6\%), Enterobacter spp. (2.7\%), Citrobacter (1.8\%) and Pseudomonas aeruginosa $(0.9 \%)$ and the antibiotic of choice was amikacin.

Male gender and bacteriuria after catheter removal were significantly associated $(P=0.021)$ meaning that removing catheter before the fifth day of transplantation leads to higher rates of UTI and bacteriuria after catheter removal. Also, female gender and bacteriuria after catheter removal were not associated $(P=0.728)$ meaning that removing catheter before the fifth day of transplantation does not increase UTI and bacteriuria after catheter removal.

One month after transplantation, the mean renal volume increase in group 1 was $78.35 \pm 24.88 \mathrm{~cm}^{3}$ and it was $65.26 \pm 7.63 \mathrm{~cm}^{3}$ in group 2. Although this volume elevation was higher in group 1 , but it was not statistically significant $(P=0.227)$. We also found that the difference of renal volume was positively correlated to renal transplant recipient and donor's age and donor's BMI $(P=0.000$, $P=0.008$ and $P=0.037$, respectively). With increasing $\mathrm{BMI}$ and age of recipient, the renal volume increased after one month but increasing donor's age leaded to renal volume decrease after one month.

The mean renal volume increased in both male and females $\left(76.99 \pm 23.08 \mathrm{~cm}^{3}\right.$ and $64.29 \pm 6.01 \mathrm{~cm}^{3}$, respectively, $P=0.258)$.

\section{Discussion}

One of the main complications after renal transplantation with serious consequences is UTI (15). These patients are also at high risk for developing bacteriuria which is dangerous for patient and the transplanted kidney (16). Treatment of patients with severe renal failure has been enhanced, especially with improvement in surgical procedures and pharmaceutical management. Nevertheless, due to immunosuppressive treatment, these patients are capable to develop postoperative infections and UTI (17). To our knowledge, this is the first study to evaluate the association between kidney size and volume with UTI and bacteriuria. Previous studies have evaluated the effect of donor kidney size on recipient outcomes. In this study bacteriuria occurred in $21.1 \%$ of the patients one month after transplantation and bacteriuria time after transplantation and catheter removal was later in group 1 which removed the catheter sooner. The study of Khosravi et al demonstrated the UTI rate of $33.56 \%$ among renal transplant recipients (5). In the studies of Rivera-Sanchez et al and Kanisauskaite et al, $33.3 \%$ and $37 \%$ of patients developed UTI $(15,18)$. Besides, it was similar to the studies of Lee et al (21\%) and Glazer et al (16.0\%) which removed the catheter before 6 days of transplantation $(2,8)$ but the reported rate of UTI was 53.69\% in Saudi Arabia (19), 77\% in Pakistan (20), and 63\% in Japan (21), which was higher than our study. Occurrence of UTI depends on many factors such as age, female gender, co-morbidity, type and amount of immunosuppression, prolonged use of Foley catheter, urological instrumentation and/or length of follow up period after kidney transplantation (3). The main reason for lower rate of bacteriuria in our study may be earlier catheter removal in comparison with other studies. Another reason may be better surgical procedures and pharmaceutical management (amikacin prophylaxis) since the time they conducted the study. Also, in previous studies, patients with structural abnormalities (reflux uropathy, bladder outlet obstruction) were studied and developed UTI but we excluded them from the study (20). In this study, the most common isolated bacteria were E. coli, Enterobacter spp., Citrobacter and P. aeruginosa. In the study of Iqbal et al, the principally isolated agents were E.coli and Pseudomonas followed by Pseudomonas, Klebsiella, and Morganella morgagn (20). It should be noted that the most frequent organisms demonstrated in renal transplant recipients are E. coli and other gram negative bacteria, such as Klebsiella spp., Enterobector spp., and $P$. aeruginosa (22). The study of Sharma et al demonstrated E. coli as a common isolate followed by Staphylococcus, Enterococcus and Pseudomonas (23). In the study of Khosravi et al, E. coli was isolated in $43.53 \%$ of cases, followed by Enterobacter spp., and P. aeruginosa (5). This study showed that early catheter removal causes less bacteriuria than later one. In the study of Iqbal et al posttransplant hospital stay and delay in removal of Foleys catheter were statistically significant factors causing UTI in transplant population (20). The study by Dantas et al also demonstrated the duration of urinary bladder catheterization as main risk factor for UTIs in posttransplant patients (24). Siskind et al found that removal of Foley catheters in live donor renal transplant recipients on postoperative day 1 decreases the risk of catheter-associated UTIs and length of hospital stay (7). It also improves patient comfort, and promotes early postoperative ambulation (8).

In the current study, the prevalence of bacteriuria in women was higher in both groups. In accordance to our study, a statistically significant higher incidence of UTI was reported by other similar studies in female patients but no significant difference was observed between gender of the patients and the incidence of UTI in the study of Khosravi et al $(5,15,16,19)$.

In accordance with other reports, we found that removing catheter before the fifth day of transplantation leads to higher rates of UTI and bacteriuria in men but not in 
women. Female patients have been reported to have a higher risk of developing UTI than men after renal transplantation (25). We did not encounter any side effects and this approach is probably more comfortable for patients. Except early catheter removal, other risk factors for UTIs like female gender, previous UTI and type II diabetes are not modifiable. So, early catheter removal appears to be an effective method to decrease UTI in these patients (8).

In our study, the mean renal volume increase in both male and females one month after transplantation but it was not associated to bacteriuria. There was a significant enlargement of the kidney size in the study of Khosroshahi et al (26). After renal transplantation, patients are routinely treated with immunosuppressive drugs to minimize the risk of allograft rejection. There are no distinguished clinical features to differentiate immunosuppressive drugs' nephrotoxicity from acute rejection. The histology can be nonspecific sometimes, with evidence of both toxicity and rejection in a single biopsy (27). A change in kidney dimensions from one examination to the next may be an important indicator of the presence or progression of disease (12). Renal length and volume also are important clinical parameters in the evaluation and follow-up of kidney transplant recipients (11).

We observed that one month after transplantation, the mean renal volume increase was higher in patients whose catheter was removed sooner but it was not statistically significant. Kidney volume provides an adequate estimate of nephron number, which, if low, increases the risk of hypertension and renal failure (28). Most of the studies have shown strong correlations between kidney volume and post-transplantation outcomes in living donor transplantation (29-31).

This study revealed that with increasing BMI and age of the recipients, the renal volume increased after one month but increasing donor's age decreased renal volume after one month. In the study of Cheong et al in both men and women, renal volumes decreased with age but this trend was not statistically significance (12).

\section{Conclusion}

This study showed that the time of catheter removal after kidney transplantation does not affect incidence of bacteriuria but increases the probability of bacteriuria in men whose catheter was removed within 5 days after transplantation. We also found that the renal volume change is not associated with catheter removal time and bacteriuria.

\section{Limitations of the study}

We had some limitations. First, its short follow-up time limited us to state with certainty that donated kidney volume predicts long-term graft survival in living renal transplantation after this time $(15,19)$. Previous studies have shown that kidney function one year after transplantation is predictive of long-term outcome (32).
We used a retrospective cohort study design to identify independent risk factors for UTI and subsequent bacteremia. There was a significant gender disproportion in this study. It is suggested to evaluate risk factors for UTI including pre-transplant urine volume, post void residual volume, and prostate volume. Longer follow-up periods will be needed to determine the real impact of kidney size on graft survival is suggested.

\section{Acknowledgements}

It is our pleasure to thank all the laboratory staff of Shahid Beheshti hospital, Babol University of Medical Sciences, Iran. We would also thank Mrs. Fatemeh Hosseinzadeh (Infectious Diseases Research Center with focus on Nosocomial Infections, Mazandaran University of Medical Sciences) for editing the manuscript.

\section{Authors' contribution}

RA, and AAP participated in all experiments, coordinated the data-analysis and contributed to the writing of the manuscript. SRF coordinated the acquisition of data. RF and AAP designed the research plan and organized the study. RA prepared the final manuscript.

\section{Conflicts of interest}

The authors declare no conflict of interest.

\section{Ethical considerations}

Ethical issues (including plagiarism, data fabrication, double publication) have been completely observed by the authors.

\section{Funding/Support}

This article is extracted from general physician thesis of SRF. This study was supported by a grant from Babol University of Medical Sciences (\#923649, 2013).

\section{References}

1. Akbarzadeh-Pasha A, Sorkhi H, Razzaghi E, Oliaei F, Gholizadeh Pasha A, Alizadeh-Navaei R, et al. Outcome of 200 kidney transplantation in kidney transplant center of Shahid Beheshti hospital in Babol (Iran). J Babol Univ Med Sci. 2012;14:82-8. [Persian].

2. Lee JR, Bang H, Dadhania D, Hartono C, Aull MJ, Satlin $\mathrm{M}$, et al. Independent risk factors for urinary tract infection and for subsequent bacteremia or acute cellular rejection: a single center report of 1166 kidney allograft recipients. Transplantation. 2013;96:732-8. doi: 10.1097/ TP.0b013e3182a04997.

3. Säemann M, Hörl W. Urinary tract infection in renal transplant recipients. Eur J Clin Invest. 2008;38 Suppl 2:5865. doi: 10.1111/j.1365-2362.2008.02014.x.

4. Ariza Heredia EJ, Beam EN, Lesnick TG, Cosio FG, Kremers WK, Razonable RR. Impact of urinary tract infection on allograft function after kidney transplantation. Clin Transplant. 2014;28:683-90. doi: 10.1111/ctr.12366.

5. Khosravi AD, Abasi Montazeri E, Ghorbani A, Parhizgari $\mathrm{N}$. Bacterial urinary tract infection in renal transplant recipients and their antibiotic resistance pattern: a four- 
year study. Iran J Microbiol. 2014;6:74-8.

6. Elkehili I, Kekli A, Zaak A, Salem E. Urinary tract infection in renal transplant recipients. Arab J Nephrol Transplant. 2010;3:53-5.

7. Siskind E, Sameyah E, Goncharuk E, Olsen EM, Feldman J, Giovinazzo K, et al. Removal of Foley catheters in live donor kidney transplant recipients on postoperative day 1 does not increase the incidence of urine leaks. Int J Angiol. 2013;22:45-8. doi: 10.1055/s-0033-1333870.

8. Glazer ES, Benedict K, Akhavanheidari M, James S, Molmenti E. Living donor renal transplant recipients tolerate early removal of bladder catheters. Int J Angiol. 2009; 18:67-68.

9. Morris P, Knechtle SJ. Kidney transplantation-principles and practice. Philadelphia: Elsevier; 2013.

10. Saeed Z, Mirza W, Sayani R, Sheikh A, Yazdani I, Ather Hussain S. Sonographic measurement of renal dimensions in adults and its correlates. Int J Collab Res Intern Med Public Health. 2012;4:1626-41.

11. Nicholson M, Windmill D, Horsburgh T, Harris K. Influence of allograft size to recipient body-weight ratio on the long-term outcome of renal transplantation. Br J Surg. 2000;87:314-9. doi: 10.1046/j.1365-2168.2000.01390.x.

12. Cheong B, Muthupillai R, Rubin MF, Flamm SD. Normal values for renal length and volume as measured by magnetic resonance imaging. Clin J Am Soc Nephrol. 2007;2:38-45. doi: 10.2215/CJN.00930306.

13. Hricak H, Lieto R. Sonographic determination of renal volume. Radiology. 1983;148:311-2. doi: 10.1148/ radiology.148.1.6344137.

14. Egberongbe AA, Adetiloye VA, Adeyinka AO, Afolabi OT, Akintomide AO, Ayoola OO. Evaluation of renal volume by ultrasonography in patients with essential hypertension in Ile-Ife, south western Nigeria. Libyan J Med. 2010;5: 4848. doi: 10.3402/ljm.v5i0.4848

15. Rivera-Sanchez R, Delgado-Ochoa D, Flores-Paz RR, García-Jiménez EE, Espinosa-Hernández R, Bazan-Borges AA, et al. Prospective study of urinary tract infection surveillance after kidney transplantation. BMC Infect Dis. 2010;10:245. doi: 10.1186/1471-2334-10-245.

16. Chuang P, Parikh CR, Langone A. Urinary tract infections after renal transplantation: a retrospective review at two US transplant centers. Clin Transplant. 2005;19:230-5. doi: 10.1111/j.1399-0012.2005.00327.x.

17. De Souza RM, Olsburgh J. Urinary tract infection in the renal transplant patient. Nat Clin Pract Nephrol. 2008;4:252-64. doi: 10.1038/ncpneph0781.

18. Kanisauskaite E, Kuzminskis V, Bumblyte I, Maslauskiene $\mathrm{R}$, Pakalnyte R. The beginning of kidney transplantation in Kaunas (results of Kaunas University of Medicine Hospital 2000-2004). Medicina (Kaunas). 2004;41:87-92. [Lithuanian].

19. Barbouch S, Cherif M, Ounissi M, Karoui C, Mzoughi $S$, Hamida FB, et al. Urinary tract infections following renal transplantation: a single-center experience. Saudi J
Kidney Dis Transpl. 2012;23:1311-4. doi: 10.4103/13192442.103586.

20. Iqbal T, Naqvi R, Akhter SF. Frequency of urinary tract infection in renal transplant recipients and effect on graft function. J Pak Med Assoc. 2010;60:826-9.

21. Nizze H, Brockmöller S, Bast R, Schmitt E. Infectious causes of death in renal transplant patients. A clinical pathological autopsy study. Verh Dtsch Ges Pathol. 1991;75:218-23.

22. Takai K, Aoki A, Suga A, Tollemar J, Wilczek H, Naito K, et al. Urinary tract infections following renal transplantation. Transplant Proc. 1998;30:3140-1.

23. Sharma KK, Ayyagiri A, Dhole TN, Prasad KN, Kishore J. Prevalence of infections in renal transplant recipients of north India. Indian J Pathol Microbiol. 2007;50:453-7.

24. Dantas S, Kuboyama R, Mazzali M, Moretti M. Nosocomial infections in renal transplant patients: risk factors and treatment implications associated with urinary tract and surgical site infections. J Hosp Infect. 2006;63:117-23. doi: 10.1016/j.jhin.2005.10.018.

25. Domann E, Hong G, Imirzalioglu C, Turschner S, Kühle J, Watzel C, et al. Culture-independent identification of pathogenic bacteria and polymicrobial infections in the genitourinary tract of renal transplant recipients. J Clin Microbiol. 2003;41:5500-10.

26. Khosroshahi HT, Tarzamni M, Oskuii RA. Doppler ultrasonography before and 6 to 12 months after kidney transplantation. Transplant Proc. 2005;37:2976-81. doi: 10.1016/j.transproceed.2005.08.003.

27. Buckley AR, Cooperberg P, Reeve CE, Magil A. The distinction between acute renal transplant rejection and cyclosporine nephrotoxicity: value of duplex sonography. AJR Am J Roentgenol. 1987;149:521-5. doi: 10.2214/ ajr.149.3.521.

28. Brenner BM, Garcia DL, Anderson S. Glomeruli and blood pressure Less of one, more the other? Am J Hypertens. 1988;1:335-47. Review.

29. Lee JH, Won JH, Oh CK. Impact of the ratio of graft kidney volume to recipient body surface area on graft function after live donor kidney transplantation. Clin Transplant. 2011;25:E647-55. doi: 10.1111/j.1399-0012.2011.01502.x.

30. Hugen CM, Polcari AJ, Farooq AV, Fitzgerald MP, Holt DR, Milner JE. Size does matter: donor renal volume predicts recipient function following live donor renal transplantation. J Urol. 2011;185:605-9. doi: 10.1016/j. juro.2010.09.098.

31. Poggio E, Hila S, Stephany B, Fatica R, Krishnamurthi $\mathrm{V}$, Del Bosque C, et al. Donor kidney volume and outcomes following live donor kidney transplantation. Am J Transplant. 2006;6:616-24. doi: 10.1111/j.16006143.2005.01225.x.

32. Hariharan S, Mcbride MA, Cherikh WS, Tolleris CB, Bresnahan BA, Johnson CP. Post-transplant renal function in the first year predicts long-term kidney transplant survival. Kidney Int. 2002;62:311-8. doi: 10.1046/j.15231755.2002.00424.x.

Copyright ( 2017 The Author(s); Published by Nickan Research Institute. This is an open-access article distributed under the terms of the Creative Commons Attribution License (http://creativecommons.org/licenses/by/4.0), which permits unrestricted use, distribution, and reproduction in any medium, provided the original work is properly cited. 